Research Article

\title{
Introduction and Application of a Simple Probabilistic Liquefaction Hazard Analysis Program: HAZ45PL Module
}

\author{
Jui-Ching Chou $\mathbb{D D}^{1}{ }^{1}$ Pao-Shan Hsieh, ${ }^{2}$ Po-Shen Lin, ${ }^{2}$ Yin-Tung Yen, ${ }^{2}$ and Yu-Hsi Lin ${ }^{3}$ \\ ${ }^{1}$ Department of Civil Engineering, National Chung-Hsing University, Taichung 40227, Taiwan \\ ${ }^{2}$ Sinotech Engineering Consultants, Inc., Taipei 11494, Taiwan \\ ${ }^{3}$ Liming Engineering Consultants Co., LTS., Taichung 40848, Taiwan \\ Correspondence should be addressed to Jui-Ching Chou; jccchou@nchu.edu.tw
}

Received 12 October 2020; Revised 1 January 2021; Accepted 8 January 2021; Published 27 January 2021

Academic Editor: Seyed Mahdi Seyed Kolbadi

Copyright (c) 2021 Jui-Ching Chou et al. This is an open access article distributed under the Creative Commons Attribution License, which permits unrestricted use, distribution, and reproduction in any medium, provided the original work is properly cited.

\begin{abstract}
The 2016 Meinong Earthquake hit southern Taiwan and many shallow foundation structures were damaged due to soil liquefaction. In response, the government initiated an investigation project to construct liquefaction potential maps for metropolitans in Taiwan. These maps were used for the preliminary safety assessment of infrastructures or buildings. However, the constructed liquefaction potential map used the pseudo-probabilistic approach, which has inconsistent return period. To solve the inconsistency, the probabilistic liquefaction hazard analysis (PLHA) was introduced. However, due to its complicated calculation procedure, PLHA is not easy and convenient for engineers to use without a specialized program, such as in Taiwan. Therefore, PLHA is not a popular liquefaction evaluation procedure in practice. This study presents a simple PLHA program, HAZ45PL Module, customized for Taiwan. Sites in Tainan City and Yuanlin City are evaluated using the HAZ45PL Module to obtain the hazard curve and to construct the liquefaction probability map. The liquefaction probability map provides probabilities of different liquefaction potential levels for engineers or owners to assess the performance of an infrastructure or to design a mitigation plan.
\end{abstract}

\section{Introduction}

The 2016 Meinong Earthquake $\left(M_{\mathrm{w}}=6.5\right)$ struck south Taiwan on February 6, 2016. The strong ground motion caused huge loss of lives (117 people dead and 504 people injured) [1]. Many shallow foundation structure in Tainan area were damaged due to soil liquefaction which thus gained considerable public attention. In response, the government initiated a project to evaluate and construct the liquefaction potential map for the urban areas of Taiwan. This map was constructed based on the liquefaction potential index (LPI) [2] which is calculated using the factor of safety against liquefaction $\left(\mathrm{FS}_{\mathrm{L}}\right)$ determined from a simplified liquefaction evaluation procedure. Engineers and owners use the liquefaction potential map to perform a preliminary safety evaluation on infrastructures or buildings and to determine the need of a mitigation plan.

The procedures for the LPI calculation in Taiwan are (1) select the design level (e.g., 475-year return period) peak ground acceleration (PGA); (2) pair PGA with a single earthquake magnitude $\left(M_{\mathrm{w}}\right)$ obtained from the deaggregation process of the probabilistic seismic hazard analysis (PSHA) at the same return period; (3) decide a representative water table level; (4) calculate $\mathrm{FS}_{\mathrm{L}}$ using a simplified liquefaction evaluation procedure with the selected PGA, $M_{\mathrm{w}}$, and water table level; and (5) estimate LPI according to the depth and $\mathrm{FS}_{\mathrm{L}}$. The estimated LPI or other related hazards are assumed to correspond to the same return period of PGA. This approach is named the "pseudoprobabilistic" approach [3-5].

In the pseudo-probabilistic approach, LPI at a site is estimated from a selected pair of PGA and $M_{\mathrm{w}}$, and $M_{\mathrm{w}}$ is assumed to have the same return period with the selected PGA. However, from the PSHA concept, a site could be subjected to numerous pairs of PGA and $M_{\mathrm{w}}$. Each pair has its own rate of occurrence. Therefore, LPI estimated from the pseudo-probabilistic approach and the selected PGA will not 
have a consistent return period as expected [2, 6-8]. As a solution to this inconsistency issue, a probabilistic approach, the performance-based earthquake engineering (PBEE) or the probabilistic liquefaction hazard analysis (PLHA), was introduced to incorporate the occurrence of the ground motion (PGA and $M_{\mathrm{w}}$ pairs) obtained from PSHA into the calculation of LPI or other liquefaction hazards [9-11].

In PLHA, engineers no longer need to select one representative pair of PGA and $M_{\mathrm{w}}$ as analysis inputs. All scenarios (PGA and $M_{\mathrm{w}}$ pairs) and their occurrence frequencies are considered in PSHA by accounting for the uncertainties of earthquake occurrence, ground-motion attenuation, and site effects. The calculation of PSHA is complicated, and thus PLHA is not easy and convenient for engineers to use without a specialized program. Recently, several simplified performance-based methods $[8,9,12-14]$ were established for engineers to perform PLHA in an approximated way. Available seismic hazard curves and deaggregation results provided by the United States Geological Survey (USGS) are used to obtain the occurrence frequency of PGA and $M_{\mathrm{w}}$ pairs in these simplified methods.

In Taiwan, without tools for PLHA, the current liquefaction analysis approach is still based on the pseudoprobabilistic approach. In addition, the simplified performance-based method mentioned above cannot be utilized because the seismic hazard curve and the deaggregation result are not yet available. This study presents a simple PLHA program, HAZ45PL Module, customized for engineers in Taiwan to obtain the LPI hazard curve. Moreover, a new application of PLHA results, the probability of exceedance map of LPI, is demonstrated. The probability information can help engineers, owners, or government agencies to carry out a performance assessment on infrastructures or prioritize a mitigation plan. In addition, because of the importance of the water table level on LPI, the HAZ45PL Module includes the uncertainty of the seasonal water table level in the LPI calculation.

\section{Methodology of HAZ45PL Module}

The HAZ45PL Module consists of HAZ45PL and R language code [15]. HAZ45PL is an executable file calculating LPI of each soil layer based on a PGA and $M_{\mathrm{w}}$ pair obtained from earthquake scenarios in PSHA. HAZ45PL is modified from HAZ45, an open source FORTRAN code developed by Dr. Norm Abrahamson for PSHA [16]. The steps of HAZ45PL Module to construct the LPI hazard curve are explained as follows: (1) generate an earthquake scenario following procedures in HAZ45; (2) provide $M_{\mathrm{w}}$ and the occurrence frequency of the earthquake scenario; (3) calculate PGA using reasonable ground-motion prediction equations (GMPE) for the earthquake scenario; (4) calculate $\mathrm{FS}_{\mathrm{L}}$ of each soil layer using PGA and $M_{\mathrm{w}}$ from Steps (2) and (3); (5) estimate LPI according to $\mathrm{FS}_{\mathrm{L}}$ from Step (4); (6) export LPI and the occurrence frequency of each soil layer; (7) repeat Steps (1)-(6) for earthquake scenarios from all seismic sources; (8) use R language code as a post-process platform to process LPI and the occurrence frequency of the corresponding PGA and $M_{\mathrm{w}}$ pairs and generate the LPI hazard curve.

The input data files of the HAZ45PL Module include the seismic source and the soil property data files. Input data of seismic sources are obtained from Central Geological Survey [17], Cheng et al. [18], and Cheng et al. [19]. In Taiwan, seismogenic sources can be categorized as follows: (1) shallow regional source, (2) deep regional source, (3) crustal active fault source, (4) subduction interface source, and (5) subduction intraslab source. Because the contribution of the deep regional source is much less comparing to other seismic sources [20], in order to shorten the analysis time, the deep regional source is not included in the current HAZ45PL Module. The needed input data of soil properties are unit weight, SPT $N$, fines content, plastic index, and clay content.

GMPEs used in the current version of the HAZ45PL Module are built in equations for regional, crustal, and subduction seismic sources. Two crustal GMPEs, Lin11 [21] and CY14 [22], are selected for regional and crustal sources. Lin11 was built using a GMPE model for the tectonic setting of Taiwan and the mostly used GMPE in Taiwan. Lin 11 includes the site response effect and the hanging wall and footwall effect on GMPE. CY14 is a GMPE from NGAWest 2 selected for considering the ground-motion prediction model uncertainty (epistemic uncertainty) in the HAZ45PL Module. CY14 was built using a GMPE model for the tectonic setting similar to Taiwan and also includes the site condition effect and the hanging wall and footwall effect on GMPE. LL08 [23] and BCH16 [24] are two GMPEs selected for subduction sources. LL08 was built using data of subduction earthquakes in Taiwan and is also the mostly used GMPE in Taiwan. BCH16 is for worldwide subduction earthquakes and selected for considering the ground-motion prediction model uncertainty (epistemic uncertainty) in the HAZ45PL Module. In the current version of HAZ45PL Module, in order to simplify the analysis process, the variation of GMPE on PGA is estimated using the three-point approximation method [25].

Five frequently used simplified liquefaction evaluation procedures for $\mathrm{FS}_{\mathrm{L}}$ calculation in Taiwan are included in the HAZ45PL Module as follows: National Center for Earthquake Engineering Research (NCEER) procedure [26], Hyperbolic Function (HBF) procedure [27], Japan Road Association (JRA) procedure [28], Tokimatsu and Yoshimi (T-Y) procedure [29], and Architecture Institute of Japan (AIJ) procedure [30]. $\mathrm{FS}_{\mathrm{L}}$ estimated from the above procedures are used to obtain LPI following equations from Iwasaki et al. [2]:

$$
\mathrm{LPI}=\sum_{i=1}^{n} F_{i} \times W_{i} \times H_{i},
$$

where $i$ is the layer number (total number of soil layers is $n$ ), $F_{i}=1-\mathrm{FS}_{L_{i}}\left(F_{i}=0\right.$ for $\left.\mathrm{FS}_{L_{i}} \geq 1\right), W_{i}=10-0.5 \quad Z_{i}$ is the weighting factor for $i^{\text {th }}$ layer and $Z_{i}$ is the depth (in meters) of 
$i^{\text {th }}$ layer, and $H_{i}$ is thickness (in meters) of $i^{\text {th }}$ layer. The liquefaction potential is categorized in four levels: (1) $\mathrm{LPI}=0$, the liquefaction potential is very low; (2) $0<\mathrm{LPI} \leq 5$, the liquefaction potential is low; (3) $5<\mathrm{LPI} \leq 15$, the liquefaction potential is high; and (4) $15<\mathrm{LPI}$, the liquefaction potential is very high. The uncertainty of the evaluation procedure of $\mathrm{FS}_{\mathrm{L}}$ on LPI is considered via the logic tree approach.

Apart from ground motion and soil properties, the variation of water table level is another important factor affecting the liquefaction potential. In the HAZ45PL Module, the variation of the water table level is included via the logic tree approach. The logic tree used in the HAZ45PL Module is shown in Figure 1. Weights and variations of GMPE are fixed while those of the water table level and the liquefaction potential calculation procedure can be adjusted by users.

\section{Applications of HAZ45PL Module}

Applications on a single location using PLHA results are demonstrated in Tainan City, and applications of PLHA results on liquefaction potential maps are demonstrated in Changhua County.

3.1. Tainan City. First, the HAZ45PL Module is applied to two sites (Annan and Xinshi Sites) in Tainan City, where a detailed investigation with 18 boreholes was performed after the 2016 Meinong Earthquake. In this study, six boreholes (BH-A1 to BH-A3 of Annan Site and BH-S1 to BH-S3 of Xinshi Site) are used for analyses. Figure 2 and Table 1 show the site locations and their information, respectively. Soil layers of Annan and Xinshi Sites are mostly Silty Sand (SM) layers or Silt (ML) layers with few Clay (CL) layers, as shown in Figure 3. Shallow SM or ML layers $(<10 \mathrm{~m})$ have relatively low SPT $N$ values $(<10)$ and water table levels are high (between 0.6 and $0.9 \mathrm{~m}$ below the ground surface). These make Annan and Xinshi Sites susceptible to liquefaction during earthquakes. Detailed investigation information refers to NCEER [31].

Hazard curves of LPI for boreholes in Annan and Xinshi Sites are shown in Figure 4 and the 475-year return period LPIs are listed in Table 2. Results of the pseudo-probabilistic approach using PGA and $M_{\mathrm{w}}$ pairs in Table 1 are also marked for comparisons. The water table used here is the water table during the site investigation, as listed in Figure 3. Effects of water table on LPI are discussed later. All listed liquefaction potential calculation procedures in Figure 1 are used and equal weights are assigned to each procedure in this analysis for simplicity. LPI hazard curves at the same site from different boreholes (BH-A1 to BH-A3 of Annan Site or BH-S1 to BH-S3 Xinshi Site) show different levels of variations because of the spatial variation and randomness of soil properties. Table 2 shows that LPIs at 475 -year return period ( $475 \mathrm{yr} \mathrm{RP}$ ) differ from those of the pseudo-probabilistic approach with $475 \mathrm{yr}$ RP PGA. In addition, return periods of LPIs of the pseudo-probabilistic approach are quite different between boreholes. The inconsistencies of LPIs and return periods are caused by the incapability of the pseudo-probabilistic approach to include the occurrence frequency of the PGA and $M_{\mathrm{w}}$ pairs. PGA and $M_{\mathrm{w}}$ pairs and their rate contributions to PGA at $475 \mathrm{yr} R \mathrm{R}$ at two sites are deaggregated and shown in Figure 5. Clearly, each PGA and $M_{\mathrm{w}}$ pair contributes differently to the total hazard and cannot be represented by only one PGA and $M_{\mathrm{w}}$ pair, such as used in the pseudo-probabilistic approach. The only way to obtain the correct LPI at $475 \mathrm{yr}$ RP is to include the occurrence frequency of all PGA and $M_{\mathrm{w}}$ pairs in the LPI estimation.

Next, BH-S1 is used to demonstrate the effects of the water table on LPI. As a continuous random variable, the variation of the water table also can be approximated using the three-point approximation method [25]. Weights are assigned to different water table levels (shown in Figure 1) as follows: (1) High Water Table: average water table (sets at the ground surface) of the high water table period with a weighting of 0.185 . (2) Yearly Average: long term water table (sets at the water table in Figure 3) with a weighting of 0.630. (3) Low Water Table: average water table (sets at $2.0 \mathrm{~m}$ below the ground surface) of the low water table period with a weighting of 0.185 . Figure 6 and Table 3 show LPI hazard curves and the pseudo-probabilistic approach results of $\mathrm{BH}$ $\mathrm{S} 1$ at different water table levels. It is obvious that the water table level has a significant impact on LPI and the return period. In the current practice, LPI is estimated using the pseudo-probabilistic approach with the high water table because engineers presume that the LPI at this water table level is relatively conservative. However, the conservativeness cannot be reasonably quantified using the pseudoprobabilistic approach. In PLHA, the water table fluctuation can be considered via a probabilistic approach and the LPI hazard curve can reasonably reflect effects of the water table fluctuation.

Other than the inconsistency in return period, another disadvantage of the pseudo-probabilistic approach is the provision of one LPI value (Tables 2 or 3 ) for engineers or owners to evaluate the need and the priority of mitigation schemes for infrastructures. For example, $\mathrm{BH}-\mathrm{S} 1$ and $\mathrm{BH}-\mathrm{A} 1$ have LPI $=20.6$ and 36.4 from the pseudo-probabilistic approach. When LPI $>15$, the liquefaction potential is very high and the mitigation plan on soil liquefaction is needed [2]. Therefore, the mitigation is necessary for infrastructures in both sites. On the contrary, PLHA can provide not only LPI but also the return period which can be converted to the probability of exceedance for $\geq$ LPI in certain exposure period (e.g., lifetime of infrastructure) using the Poisson process. Table 4 lists the probabilities of LPI $>15$ for BH-S1 


\begin{tabular}{|c|c|c|c|c|}
\hline $\begin{array}{c}\text { Seismic source } \\
\text { inputs }\end{array}$ & GMPE & $\begin{array}{l}\text { Variation of } \\
\text { GMPE }\end{array}$ & Water table level & $\begin{array}{c}\text { Liquefaction } \\
\text { potential calculation }\end{array}$ \\
\hline $\begin{array}{l}\text { Cheng et al. (2007) } \\
\text { Cheng et al. (2007) }\end{array}$ & $\begin{array}{l}\text { Crustal source } \\
\text { Lin } 11[0.5]^{*}\end{array}$ & $\begin{array}{l}95^{\text {th }} \text { percentile } \\
{[0.185]}\end{array}$ & High water table & $\frac{\text { NCEER }+P_{L}}{\mathrm{HBF}+\mathrm{P}_{\mathrm{L}}}$ \\
\hline CGS (2012) & CY14 [0.5] & Mean [0.63] & Yearly average & $J R A+P_{L}$ \\
\hline *[Weights] & $\begin{array}{l}\text { Subduction source } \\
\text { LL08 }[0.5] \\
\text { BCH }[0.5]\end{array}$ & $\frac{5^{\text {th }} \text { percentile }}{[0.185]}$ & Low water table & $\frac{\mathrm{T}-\mathrm{Y}+\mathrm{P}_{\mathrm{L}}}{\mathrm{AIJ}+\mathrm{P}_{\mathrm{L}}}$ \\
\hline
\end{tabular}

Figure 1: Logic tree used in the HAZ45PL module.

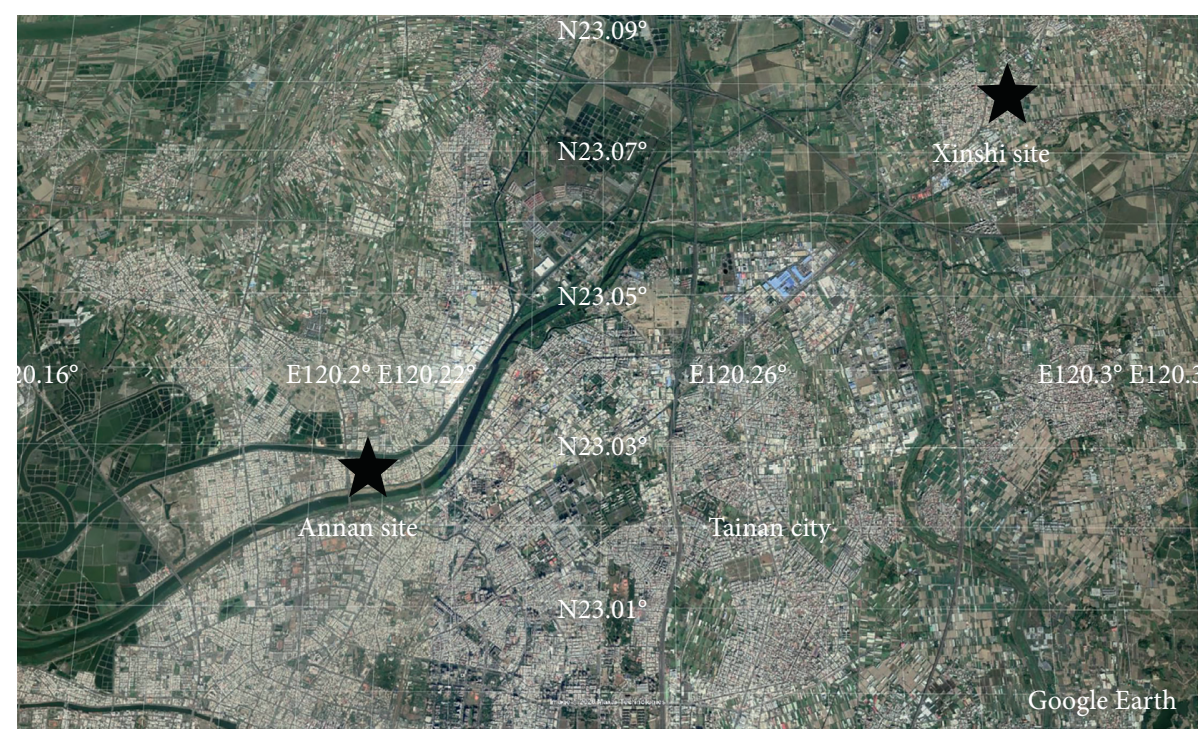

Figure 2: Location of Annan and Xinshi sites in Tainan city (from Google Earth).

TABLe 1: Information of Annan and Xinshi sites in Tainan city.

\begin{tabular}{lcc}
\hline Information & Annan site & Xinshi site \\
\hline Location (latitude, longitude) & $(23.0253,120.2074)$ & $(23.0810,120.3025)$ \\
$V{ }_{\mathrm{s} 30}(\mathrm{~m} / \mathrm{s})$ & $\sim 200 \mathrm{~m} / \mathrm{s}$ & $\sim 200 \mathrm{~m} / \mathrm{s}$ \\
PGA and $M_{\mathrm{w}}$ at 475 -year return period from HAZ45PL Module & PGA $=0.47 \mathrm{~g}$ & PGA =0.50 g \\
\end{tabular}

\begin{tabular}{|c|c|c|c|c|c|c|c|c|c|c|c|c|c|c|c|c|c|c|c|c|c|c|c|}
\hline \multicolumn{4}{|c|}{$\begin{array}{c}\text { BH-A1 } \\
\mathrm{WTD}^{1}=0.94 \mathrm{~m}\end{array}$} & \multicolumn{4}{|c|}{$\begin{array}{c}\text { BH-A2 } \\
\mathrm{WTD}^{1}=0.80 \mathrm{~m}\end{array}$} & \multicolumn{4}{|c|}{$\begin{array}{c}\text { BH-A3 } \\
\mathrm{WTD}^{1}=0.84 \mathrm{~m}\end{array}$} & \multicolumn{4}{|c|}{$\begin{array}{c}\text { BH-S1 } \\
\mathrm{WTD}^{1}=0.70 \mathrm{~m}\end{array}$} & \multicolumn{4}{|c|}{$\begin{array}{c}\text { BH-S2 } \\
\mathrm{WTD}^{1}=0.60 \mathrm{~m}\end{array}$} & \multicolumn{4}{|c|}{$\begin{array}{c}\text { BH-S3 } \\
\mathrm{WTD}^{1}=0.86 \mathrm{~m}\end{array}$} \\
\hline \begin{tabular}{|c|} 
Depth \\
$(\mathrm{m})$
\end{tabular} & Soil & $N$ & \begin{tabular}{|l|}
$\mathrm{FC}$ \\
$(\%)$
\end{tabular} & $\begin{array}{c}\text { Depth } \\
\text { (m) }\end{array}$ & Soil & $N$ & \begin{tabular}{|l|}
$\mathrm{FC}$ \\
$(\%)$
\end{tabular} & $\begin{array}{c}\text { Depth } \\
\text { (m) }\end{array}$ & Soil & $N$ & $\begin{array}{l}\text { FC } \\
(\%)\end{array}$ & \begin{tabular}{|c|} 
Depth \\
(m)
\end{tabular} & Soil & $N$ & \begin{tabular}{|l|}
$\mathrm{FC}$ \\
$(\%)$
\end{tabular} & \begin{tabular}{|c|} 
Depth \\
(m)
\end{tabular} & Soil & $N$ & $\begin{array}{l}\text { FC } \\
(\%)\end{array}$ & \begin{tabular}{|c|} 
Depth \\
(m)
\end{tabular} & Soil & $N$ & \begin{tabular}{|l|} 
FC \\
$(\%)$
\end{tabular} \\
\hline 1.50 & & 1 & 75 & 1.50 & & 0.66 & 26 & 1.50 & & 22 & 25 & 1.50 & & 11 & 22 & 1.50 & & 22.0 & 93 & 1.50 & & 5.0 & 97 \\
\hline 3.25 & & 2.5 & \begin{tabular}{|l|}
56 \\
\end{tabular} & 3.25 & & 1.33 & 79 & 3.25 & & \begin{tabular}{|l|}
1.5 \\
\end{tabular} & 24 & 3.25 & & 1 & 94 & 3.25 & & \begin{tabular}{|l}
10.0 \\
\end{tabular} & 36 & 3.25 & & 2.0 & 52 \\
\hline 5.00 & & 8 & 97 & 5.00 & & 6 & 78 & 5.00 & & 2.5 & 94 & 5.00 & & 7 & 88 & 5.00 & & 4.5 & 90 & 5.00 & & 6.0 & 90 \\
\hline 6.75 & & 1.5 & 33 & 6.75 & & 3 & 65 & 6.75 & & 10 & 63 & 6.75 & & 6 & 96 & 6.75 & & 5.0 & 92 & 6.75 & & 8.0 & 95 \\
\hline 8.50 & & 2.5 & 97 & 8.50 & & 4.5 & 86 & 8.50 & & 2 & 91 & 8.50 & & 4 & 97 & 8.50 & & 4.0 & 84 & 8.50 & & 3.0 & 97 \\
\hline 10.25 & & 11 & 51 & 10.25 & & 3.5 & 98 & 10.25 & & 8 & 47 & 10.25 & & 10 & 67 & 10.25 & & 11.0 & 75 & 10.25 & & 7.0 & 52 \\
\hline 12.00 & & 10 & 20 & 12.00 & & 18 & 20 & 12.00 & & 19 & 29 & 11.90 & & 9 & 83 & 12.00 & & 9.0 & 79 & 12.00 & & 8.0 & 88 \\
\hline 13.75 & & 28 & \begin{tabular}{|l|}
27 \\
\end{tabular} & 13.55 & & 19 & 48 & 13.75 & & 12 & 32 & 13.75 & & 10 & 98 & \begin{tabular}{|l|}
13.75 \\
\end{tabular} & & 14.0 & 96 & 13.75 & & 12.0 & 94 \\
\hline 15.50 & & 15 & 25 & 15.30 & & 18 & 44 & 15.50 & & 3 & 57 & 15.50 & & 8 & 84 & 15.50 & & 6.0 & 89 & 15.50 & & 10.0 & 94 \\
\hline 16.45 & & 24 & 36 & 17.05 & & 17 & 38 & 18.00 & & 37 & 16 & 17.25 & & 7 & 86 & \begin{tabular}{|l|}
17.25 \\
\end{tabular} & & 13.0 & 82 & 17.25 & & 15.0 & 85 \\
\hline 18.00 & & 31 & 28 & 18.80 & & 42 & 16 & 20.00 & & 25 & 26 & 19.00 & & 13 & 99 & 19.00 & & 15.0 & 97 & 19.00 & & 13.0 & 79 \\
\hline & & & & 19.50 & & 28 & 17 & & & & & 20.00 & & 11 & 100 & 20.00 & & 12.0 & 97 & 20.00 & & \begin{tabular}{|l|}
19.0 \\
\end{tabular} & 70 \\
\hline
\end{tabular}

FIgURE 3: Investigation results of boreholes. 


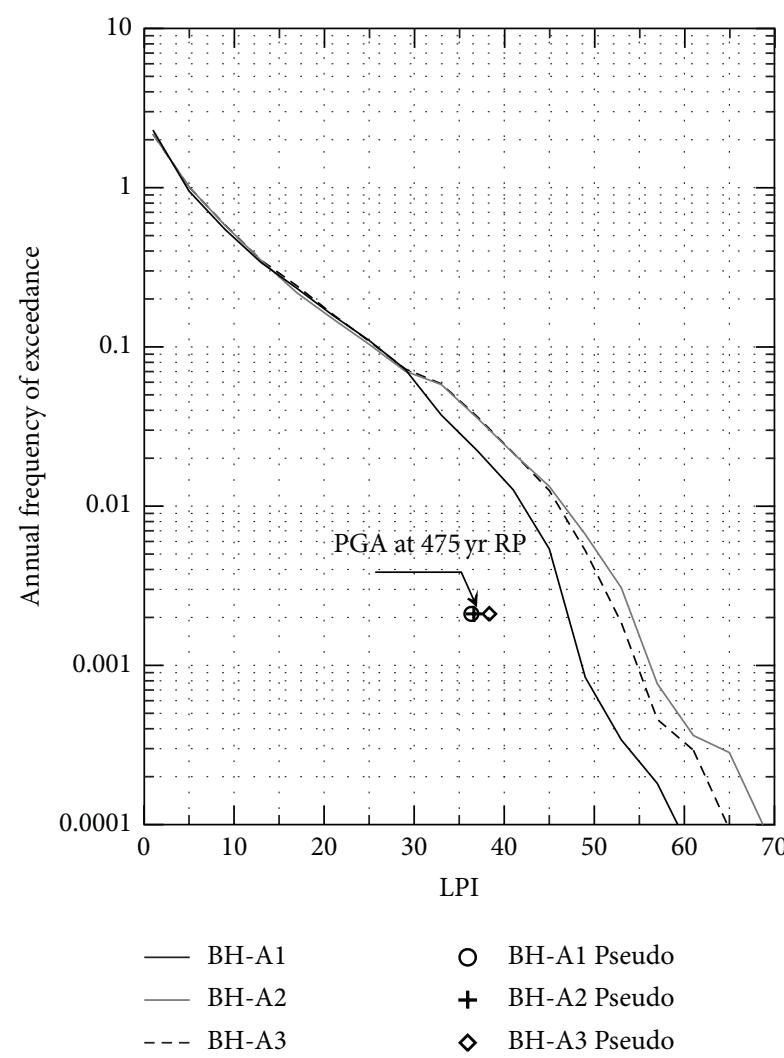

(a)

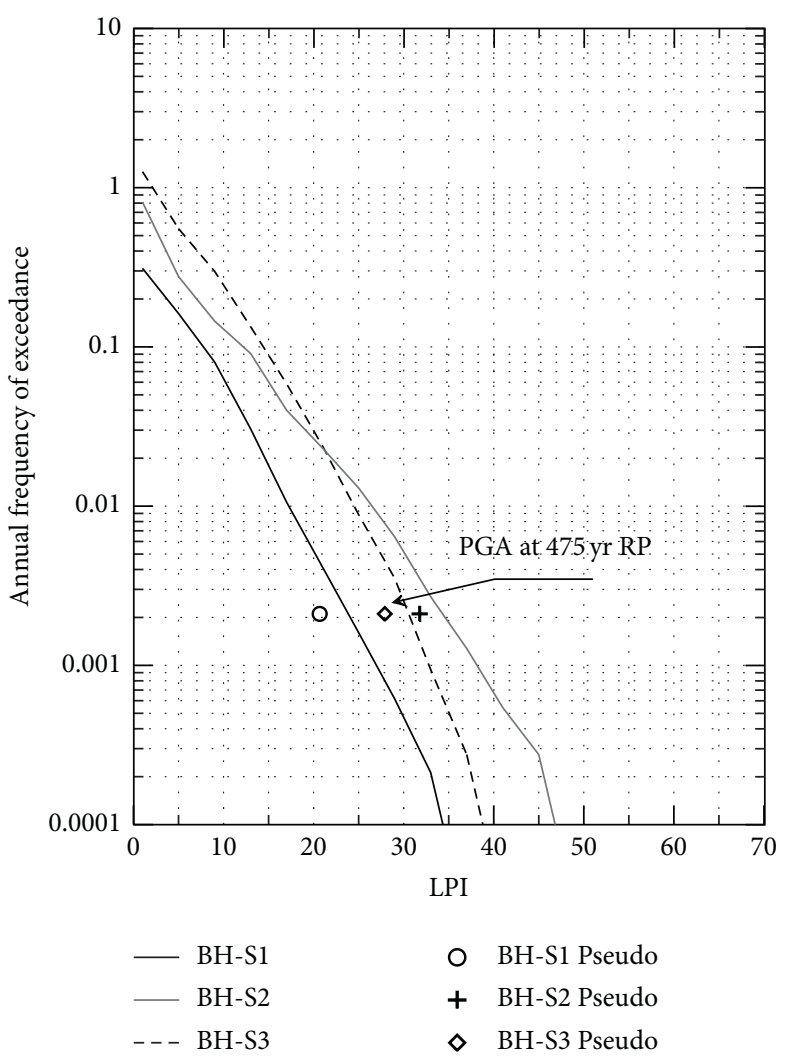

(b)

Figure 4: Hazard curves of LPI from the HAZ45PL Module. (a) Annan site and (b) Xinshi site.

TABle 2: LPI results of Annan and Xinshi sites in Tainan city.

\begin{tabular}{|c|c|c|c|c|c|c|c|}
\hline \multirow{2}{*}{ Liquefaction analysis approach } & & \multicolumn{3}{|c|}{ Annan site } & \multicolumn{3}{|c|}{ Xinshi site } \\
\hline & & BH-A1 & $\mathrm{BH}-\mathrm{A} 2$ & $\mathrm{BH}-\mathrm{A} 3$ & $\mathrm{BH}-\mathrm{S} 1$ & $\mathrm{BH}-\mathrm{S} 2$ & $\mathrm{BH}-\mathrm{S} 3$ \\
\hline \multirow{2}{*}{ Pseudo-probabilistic approach with PGA at 475 -year RP1 } & LPI & 36.4 & 36.6 & 38.3 & 20.6 & 31.8 & 27.9 \\
\hline & RP year & 45 & 28 & 33 & 222 & 333 & 238 \\
\hline PLHA at 475 -year RP & LPI & 46.5 & 54.5 & 52.5 & 24.0 & 33.5 & 30.5 \\
\hline
\end{tabular}

$\mathrm{RP}=$ return period.

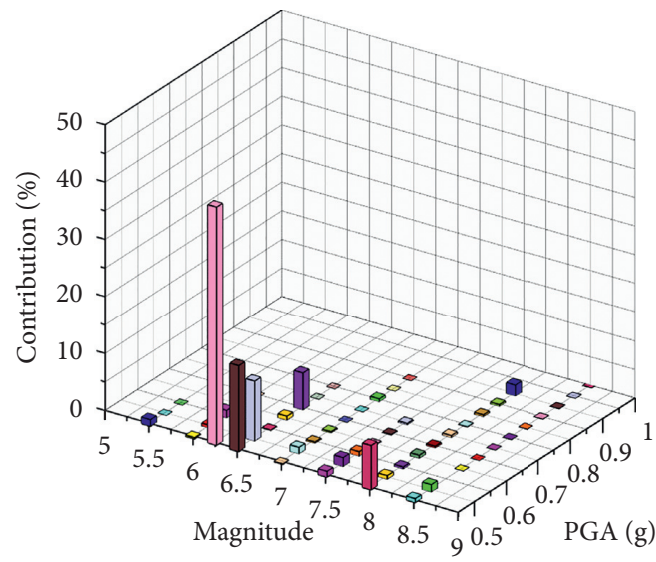

(a)

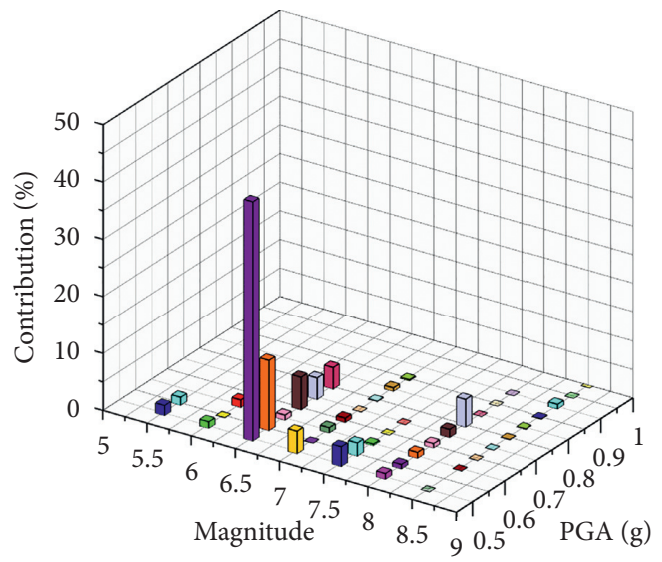

(b)

FIGURE 5: Deaggregation results of PGA at 475-year return period. (a) Annan site and (b) Xinshi site. 


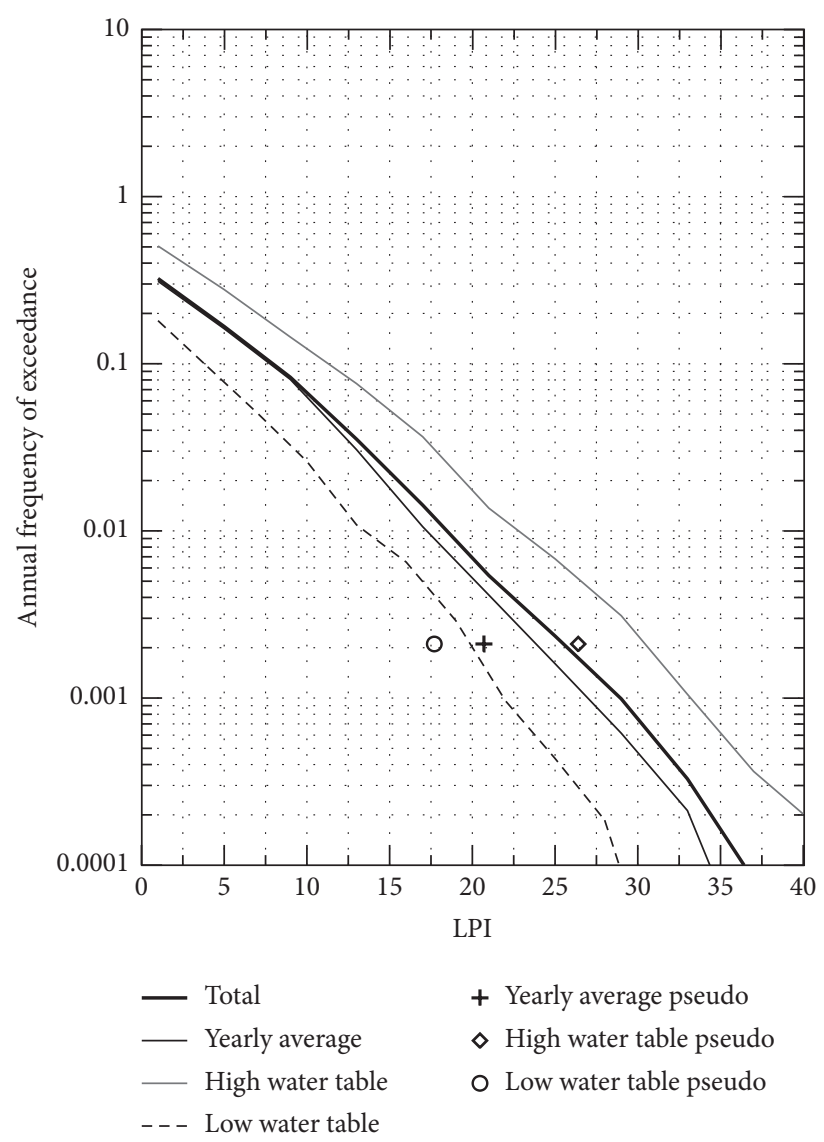

Figure 6: Total and unweighted LPI hazard curves from different water table levels of BH-S1.

TABLE 3: Results of BH-S1 at different water table levels.

\begin{tabular}{lcccc}
\hline & & High water level & Average water level & Low water level \\
\hline \multirow{2}{*}{ Pseudo-probabilistic approach with PGA at 475-year RP } & LPI & 26.4 & 20.7 & 17.7 \\
& RP & 630 & 90 & 25.5 \\
\hline PLHA at 475-yr RP & LPI & & 250 \\
\hline
\end{tabular}

TABle 4: Probability of LPI > 15 during different exposure time periods.

\begin{tabular}{lccc}
\hline & Return period at LPI $>15$ & Exposure time 100 years $(\%)$ & Exposure time 50 years $(\%)$ \\
\hline BH-A1 & 5-year & 99.9 & 99.9 \\
BH-S1 & 52-year & 85.6 & 62.1 \\
\hline
\end{tabular}

and $\mathrm{BH}-\mathrm{A} 1$ during different exposure periods as a reference. Engineers or owners can easily and rationally make the final design decision according to the probability information.

3.2. Changhua County. The HAZ45PL Module is applied to Yuanlin City, Changhua County (Figure 7), to demonstrate the construction of the liquefaction potential contour maps (Figures 8 and 9) using the Kriging method. In Figure 8, liquefaction potential levels follow the guidelines in Iwasaki et al. [2]. Comparing Figures 8(a) and 8(b), the pseudo-probabilistic approach obviously underestimates the liquefaction potential. In Figure 8(b), the east side of Yuanlin City is at a very high liquefaction potential. For future infrastructure or mitigation projects in this area, engineers and owners must 


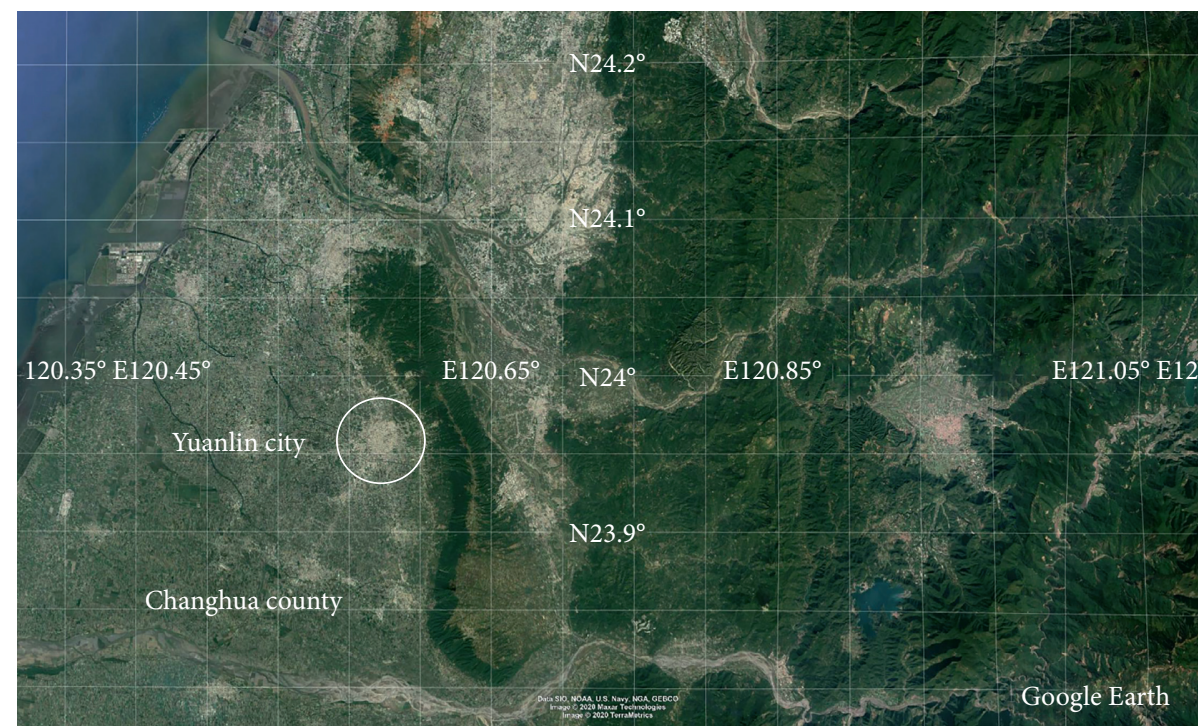

FIgURe 7: Location of Yuanlin City, Changhua County (from Google Earth).

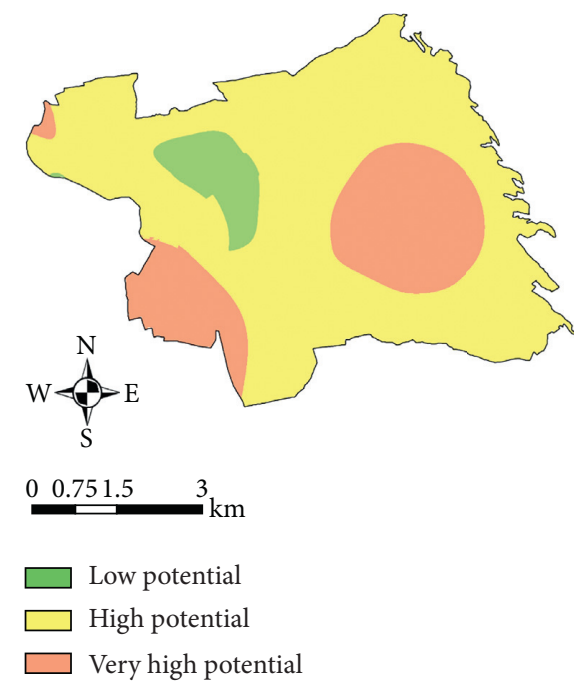

(a)

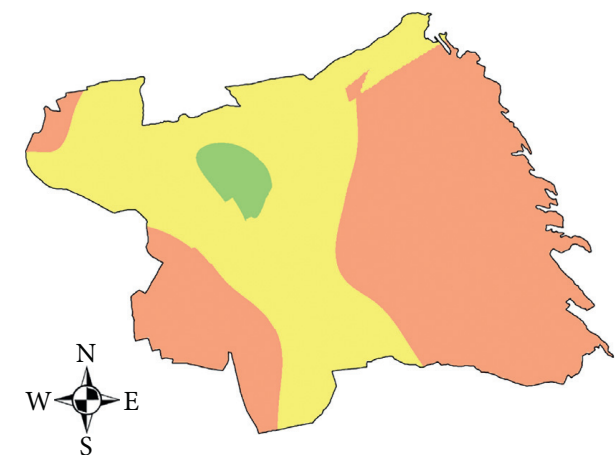

\begin{tabular}{lll}
0 & $0.751 .5 \quad 3$ \\
\hline
\end{tabular}

Low potential

High potential

Very high potential

(b)

Figure 8: Liquefaction potential level at 475-year return period. (a) Pseudo-probabilistic approach and (b) PLHA.

optimize the mitigation plan and prioritize the site. As mentioned earlier, PLHA can provide the probability of exceedance in different exposure periods. Figure 9 shows probabilities of exceedance having LPI $\geq 5$ (high liquefaction potential) and LPI $\geq 15$ (very high liquefaction potential) in 50 years. Inside the very high liquefaction potential level area (the east side of Yuanlin City), probabilities in Figure 9(b) are divided into three groups
$20 \%-40 \%, 40 \%-60 \%$, and $60 \%-80 \%$. Comparing to use only Figure 8 (b) as a reference, engineers or owners can make reasonable choices on the construction site or the mitigation plan for infrastructures or other buildings based on the probability information shown in Figure 9 (b). The probability information also provides a valuable reference for the government to make an appropriate emergency response and evacuation plan. 


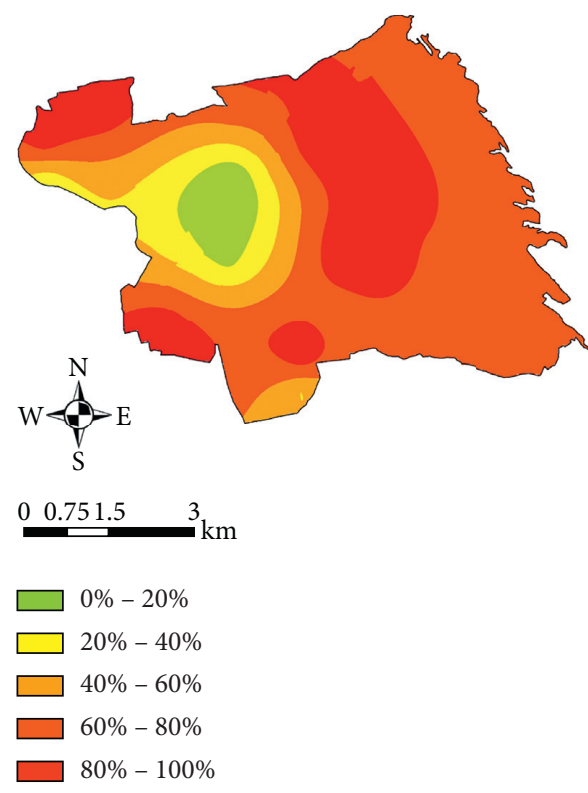

(a)

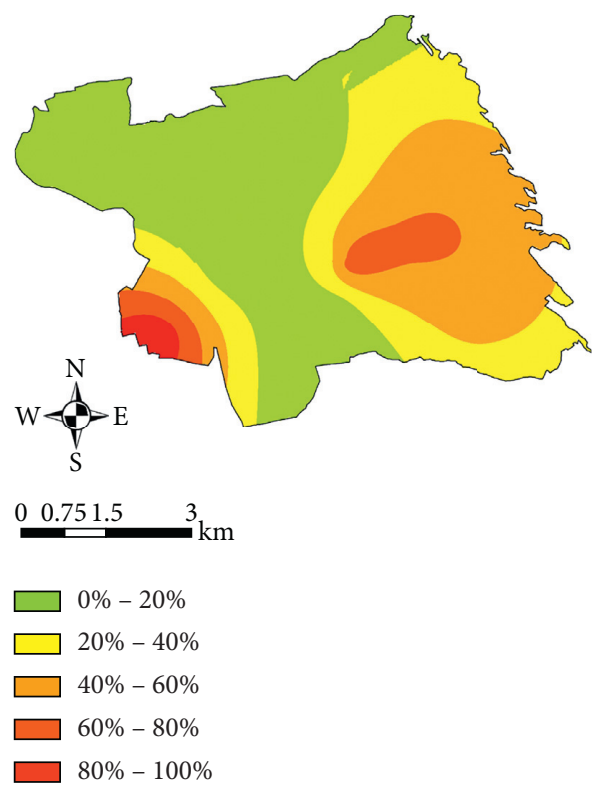

(b)

FIgURE 9: Liquefaction probability map. (a) Prob. of exceedance having LPI $\geq 5$ in 50 years and (b) prob. of exceedance having LPI $\geq 15$ in 50 years.

\section{Conclusions}

After the 2016 Meinong Earthquake, in response of the public concern on the soil liquefaction hazard, the central government initiated a project to evaluate and construct the liquefaction potential map. The common procedure used for constructing these maps is called the pseudo-probabilistic approach, which uses a pair of PGA and $M_{\mathrm{w}}$ at the selected return period with a "representative" water table level to estimate LPI for the map. The use of the pseudo-probabilistic approach has two weakness points: (1) the inconsistent return period of the estimated LPI and (2) the difficulty to select a representative water table level. PLHA was introduced to incorporate the occurrence of the ground motion (PGA and $M_{\mathrm{w}}$ pairs) into LPI calculation to solve the inconsistency issue. In addition, the difficulty of water table level selection can also be solved in PLHA via the logic tree or the probability density function. However, given the lack of an appropriate tool, PLHA is not popular in Taiwan. In this study, a simple PLHA program, HAZ45PL Module, is developed for engineers in Taiwan to obtain the LPI in a probabilistic way.

The HAZ45PL Module is applied to two selected sites to demonstrate the use of PLHA results, the hazard curve of LPI and the liquefaction probability map. With the LPI hazard curve and the Poisson process, PLHA can provide the probability of exceedance information to construct liquefaction probability maps, which enable engineers or owners to easily assess the performance of an infrastructure or to design a mitigation plan. The government can make an emergency response and evacuation plan according to the liquefaction probability map too. The liquefaction probability map was not introduced or used in previous PLHA studies.
In the current HAZ45PL Module, to keep the calculation simple and easy, the variability of the liquefaction resistance of soil is not included and the variations of PGA from GMPE are estimated using the three-point approximation. The ongoing modification of the HAZ45PL Module addresses these issues. Moreover, using the liquefaction potential only can indirectly assess the infrastructure or facility safety. In the next version of the HAZ45PL Module, the probability of liquefaction-related hazards (e.g., settlement of structure and uplift of underground structure) can be incorporated to provide a direct assessment.

\section{Data Availability}

The data used to support the findings of this study are available from the corresponding author upon request.

\section{Conflicts of Interest}

The authors declare that they have no conflicts of interest.

\section{Acknowledgments}

This research was funded by Central Geological Survey, MOEA, Taiwan, and Sinotech Engineering Consultants, Inc. The authors would like to thank staff of Central Geological Survey for providing necessary assistance and valuable expertise.

\section{References}

[1] Central Weather Bureau, 2020, https://scweb.cwb.gov.tw/zhtw/page/disaster/6.

[2] T. Iwasaki, K. Tokida, and F. Tatsuoka, "Soil liquefaction potential evaluation with use of the simplified procedure," in 
Proceedings of the International Conference on Recent Advances in Geotechnical Earthquake Engineering and Soil Dynamics, St. Louis, MO, USA, 1981.

[3] T. J. Katona, E. Györi, and L. Tóth, "Applicability of pseudoprobabilistic method of liquefaction hazard assessment for nuclear power plants at diffuse seismicity sites," Science and Technology of Nuclear Installations, vol. 2019, 2019.

[4] K. W. Franke, B. N. Lingwall, T. L. Youd, J. Blonquist, and J. H. Liang, "Overestimation of liquefaction hazard in areas of low to moderate seismicity due to improper characterization of probabilistic seismic loading," Soil Dynamics and Earthquake Engineering, vol. 116, pp. 681-691, 2019.

[5] E. M. Rathje and G. Saygili, "Probabilistic seismic hazard analysis for the sliding displacement of slopes: scalar and vector approaches," Journal of Geotechnical and Geoenvironmental Engineering, vol. 134, no. 6, pp. 804-814, 2008.

[6] K. W. Franke and S. L. Kramer, "Procedure for the empirical evaluation of lateral spread displacement hazard curves," Journal of Geotechnical and Geoenvironmental Engineering, vol. 140, no. 1, pp. 110-120, 2014.

[7] C. H. Juang, D. K. Li, S. Y. Fang, Z. Liu, and E. H. Khor, "Simplified procedure for developing joint distribution of a max and $M_{\mathrm{w}}$ for probabilistic liquefaction hazard analysis," Journal of Geotechnical and Geoenvironmental Engineering, vol. 134, no. 8, pp. 1050-1058, 2008.

[8] R. T. Mayfield, S. L. Kramer, and Y. M. Huang, "Simplified approximation procedure for performance-based evaluation of liquefaction potential," Journal of Geotechnical and Geoenvironmental Engineering, vol. 136, no. 1, pp. 140-150, 2010.

[9] C. H. Cramer, G. J. Rix, and K. Tucker, "Probabilistic liquefaction hazard maps for Memphis, Tennessee," Seismological Research Letters, vol. 79, no. 3, pp. 416-423, 2008.

[10] J. H. Hwang, C. H. Chen, and C. H. Juang, "Liquefaction hazard analysis: a fully probabilistic method," in Proceedings of the Sessions of the Geo-Frontiers 2005 Congress, Earthquake Engineering and Soil Dynamics (GSP 133), R. W. Boulanger, M. Dewoolker, and N. Gucunski, Eds., ASCE, Austin, TX, USA, January 2005.

[11] S. L. Kramer and R. T. Mayfield, "Return period of soil liquefaction," Journal of Geotechnical and Geoenvironmental Engineering, vol. 133, no. 7, pp. 802-813, 2007.

[12] M. S. Dhar and C. H. Cramer, "Probabilistic seismic and liquefaction hazard analysis of the Mississippi embayment incorporating nonlinear effects," Seismological Research Letters, vol. 89, no. 1, pp. 253-267, 2018.

[13] K. W. Franke, K. J. Ulmer, L. T. Ekstrom, and J. F. Meneses, "Clarifying the differences between traditional liquefaction hazard maps and probabilistic liquefaction reference parameter maps," Soil Dynamics and Earthquake Engineering, vol. 90, pp. 240-249, 2016.

[14] C. H. Juang, C. Y. Ou, C. C. Lu, and Z. Luo, "Probabilistic framework for assessing liquefaction hazard at a given site in a specified exposure time using standard penetration testing," Canadian Geotechnical Journal, vol. 47, no. 6, pp. 674-687, 2010.

[15] R Core Team, A Language and Environment for Statistical Computing, R Foundation for Statistical Computing, Vienna, Austria, 2018, https://www.R-project.org/.

[16] Pacific Gas \& Electric Company, Verification of PSHA code Haz43, GEO.DCPP.10.03 Rev 0, 2010.

[17] Central Geological Survey, 2020, http://fault.moeacgs.gov.tw/ TaiwanFaults_2009/Page Content. aspx?type=C\&id=5.

[18] C. T. Cheng, P. S. Hsieh, P. S. Lin, Y. T. Yen, and C. H. Chan, "Probability seismic hazard mapping of Taiwan," in
Encyclopedia of Earthquake Engineering, p. 25, Springer, Berlin Heidelberg, 2015.

[19] C. T. Cheng, S. J. Chiou, C. T. Lee, and Y. B. Tsai, "Study on probabilistic seismic hazard maps of Taiwan after Chi-Chi earthquake," Journal of GeoEngineering, vol. 2, no. 1, pp. 19-28, 2007.

[20] C. T. Cheng, Uncertainty Analysis and Deaggregation of Seismic Hazard in Taiwan, Ph.D. Thesis, National Central University, Chung-Li, Taiwan, 2002.

[21] P. S. Lin, C. T. Lee, C. T. Cheng, and C. H. Sung, "Response spectral attenuation relations for shallow crustal earthquakes in Taiwan," Engineering Geology, vol. 121, no. 3-4, pp. 150-164, 2011.

[22] B. S.-J. Chiou and R. R. Youngs, "Update of the Chiou and Youngs NGA model for the average horizontal component of peak ground motion and response spectra," Earthquake Spectra, vol. 30, pp. 1117-1153, 2014.

[23] P. S. Lin and C. T. Lee, "Ground-motion attenuation relationships for subduction-zone earthquakes in northeastern Taiwan," Bulletin of the Seismological Society of America, vol. 98, no. 1, pp. 220-240, 2008.

[24] N. Abrahamson, N. Gregor, and K. B. C. Addo, "Hydro ground motion prediction equations for subduction earthquakes," Earthquake Spectra, vol. 32, no. 1, pp. 23-44, 2016.

[25] D. L. Keefer and S. E. Bodily, "Three-point approximations for continuous random variables," Management Science, vol. 29, no. 5, pp. 595-609, 1983.

[26] T. L. Youd, I. M. Idriss, R. D. Andrus et al., "Liquefaction resistance of soils: summary report from the 1996 NCEER and 1998 NCEER/NSF workshops on evaluation of liquefaction resistance of soils," Journal of Geotechnical and Geoenvironmental Engineering, ASCE, vol. 127, no. 10, pp. 817833, 2001.

[27] J. H. Hwang, C. H. Chen, and C. H. Juang, "Calibrating the model uncertainty of the HBF simplified method for assessing liquefaction potential of soils," Sino-geotechnics, vol. 133, pp. 77-86, 2012, (in Chinese).

[28] Japan Road Association (JRA), Specification for Highway Bridges, Part V: Seismic Design, Japan Road Association, Japan, 1996.

[29] K. Tokimatsu and Y. Yoshimi, "Empirical correlation of soil liquefaction based on SPT N-value and fines content," Soils and Foundations, vol. 23, no. 4, pp. 56-74, 1983.

[30] Architecture Institute of Japan (AIJ), Recommendations for Design of Building Foundations, Architectural Institute of Japan, Japan, 2001, in Japanese.

[31] National Center for Research on Earthquake Engineering (NCREE), Research Report, National Center for Research on Earthquake Engineering, Taiwan, 2016, in Chinese. 